Whistle-blower's charter on the way

Sir — The gagging of research scientists against the public interest, of which John Ziman writes, will become more difficult next year, at least in the United Kingdom (Nature 395, 856-857; 1998). The Public Interest Disclosure Act was passed with allparty support in July 1998 and, according to the Department of Trade and Industry, will take effect early next year.

The act protects an employee who discloses that their employer is party to a criminal offence, is failing to fulfil a legal obligation, is endangering health and safety, or is damaging the environment. The disclosure must be made in good faith and not for personal gain. If these conditions are met, the act declares void any clause in the employee's contract that forbids disclosure. The employee is protected against dismissal for making the disclosure and against "being subjected to any detriment" by the employer. Industrial tribunals will process claims and

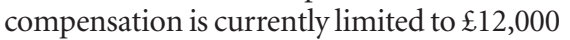
(US\$19,900), but the government is committed to removing this limit.

The employee must take the matter up with the employer first and, if it is not resolved, can then disclose it more widely. Government employees can inform the relevant minister directly. The delay in implementing the act has resulted from the need to make regulations specifying who employees in other professions should inform and how long they should give employers to act before going public.

The act will create unprecedented transparency in scientific work, as in all other fields of employment. If it had already been in force, for example, the risks of bovine spongiform encephalopathy would have been made public earlier and acted on more quickly, and the mortality rates of patients of certain surgeons at Bristol Royal Infirmary might well have been reported and investigated earlier. Laurie Smith 23 Pine Walk, Carshalton, Surrey SM5 4ES, UK

\section{It will take more than notebooks to stop fraud}

Sir - In response to your editorial, "Surviving misconduct is one thing, accountability is another", as individuals who have been embroiled in the process we find the recommendations offered to be laudable (Nature 395, 727; 1998). However, we would like to offer the following observations regarding the daunting task of interpreting laboratory records, some dated more than 10 years ago.

It is not sufficient that institutions should require "good laboratory notebooks" to be kept, and archive them for 10 years. More attention should be given to the process by which laboratory data are recorded. Each laboratory and each scientist has different standards and methods of recording data. Notebooks are highly individualized. As a result, even review of the data contained in "good" notebooks after ten years is opaque to those not involved in the experiments, and in many cases to the experimenters themselves.

Even the best notebooks suffer too many lapses in the recording of data to provide an unequivocal picture of the experiments and the results obtained. Such shortcomings make trying to reconstruct what may have gone wrong a decade earlier difficult, if not impossible.

We suggest the adoption of a standardized recording protocol like that used in medicine. Medical records serve to establish standard procedures. Laboratory research records should adhere to guidelines established by the institution for the recording of data obtained from specific procedures. These records should address certain components in the recording of data from standard procedures used by most labs. In this manner, a uniformity in the recording of data would be established that would serve (as a medical chart does) not only to allow those procedures to be reproduced but also as a detailed record which adheres to a commonly accepted standard for certain lab procedures.

In the absence of standardized guidelines, the review of individualized notebooks and the ability of researchers to adhere to "institutional" targets will fall short of providing a mechanism for preventing misconduct and ensuring accountability in research. Enforcement from above is one thing, but it is equally important to establish consistent procedures for the education of staff in recording data.

This would aid the scientific community and help minimize the adversarial episodes that can emerge from the lack of common guidelines.

Kimon Angelides

Durham University,

Durham DH1 3HP, UK

James V. Pianelli

McGehee and Pianelli, LLP,

1225 N. Loop West, Suite 810,

Houston, Texas 77008-1761, USA

\section{Time to bury misleading myth about careers}

Sir - It was with great sadness that I read of the suicide of Jason Altom, a troubled chemistry graduate student caught in the grip of an over-competitive research arena with too little academic guidance (Nature $395,823 \& 826 ; 1998)$. The minds of many of our brightest young scientists are still clouded with the notion that, once they enter the $\mathrm{PhD}$ pipeline, there is no escape save for success (tenure-track research in academia) or failure (at best, industrial postgraduate research; at worst, a terminal masters degree).

Too often, the élite academic research system perpetuates this myth through an ignorance of the notion of alternative scientific careers.

I received less immediate support than I expected during my graduate studies, and was forced to seek advice beyond my thesis adviser. Through support from others, I sought an alternative career. I now have a fulfilling career in scientific publishing, where I have been able to combine my love of science and communications.

Similar alternative career possibilities exist in education, technology transfer and law, for those students who are willing to become informed and risk the (undeserved) stigma of leaving the pipeline from another exit (see Careers and Recruitment in this issue, pages 493-496).

Your editorial and report outlined some efforts by concerned scientists and academicians to address this issue. Another recent article proposes that it is the responsibility of graduate programmes to provide their students with a range of mentoring opportunities beyond that of the traditional principal investigator and to ensure that they have access to support services, but students must also take more responsibility for their own support needs (New Anat. 253, 132-134; 1998).

Surely, much has been written on this subject since the $\mathrm{PhD}$ glut of the 1990s took centre stage among the worries of our next generation of researchers. Now, words are no longer enough; action is essential.

\section{Mark H. Paalman}

The Anatomical Record,

3241 Blackwalnut Drive,

Annapolis, Maryland 21403-4652, USA 